\title{
IMPLEMENTATION OF ACTIVITIES FOR THE EVALUATION OF THE "SPECIFIC INSTRUMENTAL" TRANSVERSAL COMPETENCE IN SUBJECTS IN THE AREA OF MECHANICAL ENGINEERING
}

\author{
A.M. Pedrosa, E.M. Sánchez-Orgaz, E. Lozano-Mínguez, S. Martínez-Sanchís \\ Universitat Politècnica de València (SPAIN)
}

\begin{abstract}
Most of the higher education frameworks work and evaluate transversal competences, to achieve the excellence of graduates, not only academically but also integrating social aspects, ethics, communication, teamwork, etc. To this end, the present work studies a common methodology both in the activities, to improve the acquisition of the "Specific Instrumental" transversal competence, as well as in its evaluation.

In the practical sessions, the student uses a detailed tutorial with the procedure to obtain the numerical result. The evaluation of the "Specific Instrumental" transversal competence is deficient following this structure since it does not show whether the student acquires autonomy to solve similar problems. Therefore, an unguided alternative activity was proposed at the end of each session, which allows us to see the evolution of the student in the face of a different problem without guidelines.

Experience shows that it is rash to expect the student to handle the program autonomously in the first session. For this reason, the activity deadline will be extended by a few weeks. Obviously, the guarantee of authenticity is lost, but responsibility for learning is transferred to the student. Allowing the student to spend the required time for deep learning, without the pressure of ending the session.
\end{abstract}

Keywords: competence, methodology, evaluation, specific instrumental, learning, finite element software.

\section{INTRODUCTION}

Work and evaluation of soft skills are included in most of the higher education frameworks in the world [1-3]. In Europe, soft skills are incorporated in the study plans following the Tuning project guidelines [4-5] which was defined by the European Higher Education Area (EHEA). In this context, the Universitat Politècnica de València (UPV) has been working on its own project for many years. The local project is known as Transversal Competences [6], and it is focused on the completion of the specific formation of the grades with skills demanded on the nowadays-professional profiles. This project includes a wider ambit than the academic, integrating social, ethics, communication or teamwork aspects, among others. All the initiatives carried out in the context of the educational project have as a main objective, to provide the excellence to the graduates, not only for their professional development, but also to obtain national (ANECA in Spain) [7] or international (ABET) accreditations [8].

The design of the activities described in this work emerge from the educational program of the UPV "Innovation and Improvement of Education Project", PIME in Spanish. Lecturers of several subjects of the Mechanical Engineering Department have proposed and worked on different activities aiming to improve the acquisition of technological abilities, which are included in the generic instrumental competences in the Tuning project [5]. This competence focuses on the use of tools and technologies necessary for professional applications. The main goal of this work is to find a common methodology both in the activities to improve the acquisition of the competence, as well as in its evaluation. The equivalent to this competence in the UPV project is called "Specific Instrumental" transversal competence, for this reason from now and in advance, in this work the UPV name of the competence will be used.

In the mechanical design of machine parts, it is necessary to select a proper material, to model the contour conditions, and to apply the adequate fail criteria. These aspects within the theory related to the mechanical problem are explained in the theoretical sessions of the subjects. The associated calculations can be carried out with a Finite Element Method (FEM) package [9], which is a common tool on the professional development of the Mechanical Engineers. 
The software explained in the practical sessions of the subjects is ANSYS ${ }^{2}$ [10], because it is one of the best commercial FEM packages and is widely used as a professional tool. The practical sessions have two outlooks: they provided a strong complement of the theoretical concepts and, at the same time, every step of the model process is properly justified under a theoretical point of view. When it is possible, in the detailed instructions given to the students, several alternatives are explained to obtain the same result. All the options are provided with a detailed description of the convenience of each one of them depending on the context.

\section{OBJECTIVES}

The main goal of the current work is focused on the search and development of activities that allow students to evaluate the "Specific Instrumental" transversal competence in a similar way in the practical sessions of different subjects belonging to the Mechanical Engineering Area. These subjects have in common that in all of them the FE program ANSYS $\otimes$ is used.

\section{METHODOLOGY}

First, the framework where the activities related to the "Specific Instrumental" transversal competence acquisition have been developed will be described. This competence is focused on the use of tools oriented towards professional services, the work developed has been carried out in practical sessions of the selected subjects. The different activities proposed have been designed for the FE tool ANSYS ${ }^{\circledR}$. The subjects chosen are given by the Mechanical Engineering Area from the Mechanical and Materials Engineering Department of the UPV, and the competence has been only measured in those practical sessions using the above-mentioned FE program. Among the subjects, some of them explain the FEM itself, like Numerical Methods which belongs to the 3rd year of the Biomedical Engineering Degree, and others are related to the Design of Machines field in which the FEM is used a work tool, such as Technology of Machines for Leveling from the Master's Degree in Industrial Engineering and Behaviour of Materials in Service from the Master's Degree in Mechatronics. The two last subjects have practically the same scope, for this reason they are turned into one, which will be called Technology of Machines from now on.

All the practical sessions involved in the current work, despite belonging to different degrees and subjects, have in common the same structure. In all of them, different problems are proposed according to the different subjects or sessions since they are adapted to the different contents and levels. The problems have in common that they can be represented by a partial derivative equation (PDE) that together with the boundary conditions lead to a particular numerical solution. The structure of practical sessions consisted in providing to the student a very detailed guide, where the steps to follow during the session to achieve the numerical result are explained. On many occasions, this numerical result can be compared to those provided by the bibliography. In the practical session guide, the proper working of the program is explained, as well as the partial results obtained at every step. Thus, the student can become familiar with problems commonly appearing in the Mechanical Engineering field.

Nevertheless, when practical sessions are structured in this way, the evaluation of "Specific Instrumental" transversal competence is deficient since it does not allow to show if the student has autonomy enough to solve analogue problems on his/her own. For this reason, an alternative activity was proposed at the end of every practical session to assess the evolution of the student when facing a different problem without any kind of instruction. The problem to solve was based on the same PDE but applied to a different geometry. Besides, the boundary conditions were not always the same as in the original problem.

The main objective of including this new activity without guiding it is that the student's attitude during the practical sessions become more participative and proactive. The strategy is to help awaken the student's interest in learning about the meaning of each step and decisions they should make when solving the problem rather than simply reproducing them on the computer. This learning is essential to correctly solve the individual problem proposed, since it implies to follow the right steps in ANSYS®, such as: setting up the program menu, defining the domain applying simplifications, defining the materials characteristics, choosing the kind and size of the elements discretizing the domain, applying the boundary conditions, etc. The student must be conscious of his/her own responsibility regarding the learning proposed in the practical sessions. In addition, the incorporation of this novelty has had a 
low cost because the most part of the practical sessions structure has been retained, as well as the lecturing resources.

In the different subjects, the number of practical sessions and their duration is the same, while the number of students significantly varies according to the degree to which the subject belongs. Besides, the practical lectures were given by different lecturers, sometimes unrelated to the design of the activity because the Teaching Management Program was previously defined and it is not possible to make changes due to overlaps with other schedules. All the information about the different subjects by subject and group can be found in Table 1.

Table 1. Practical sessions by subject.

\begin{tabular}{|c|c|c|c|c|}
\hline Subject and Year & $\begin{array}{l}\text { Number of } \\
\text { students }\end{array}$ & $\begin{array}{c}\text { Number of } \\
\text { practical } \\
\text { sessions }\end{array}$ & $\begin{array}{c}\text { Session } \\
\text { duration (h) }\end{array}$ & $\begin{array}{l}\text { Number of } \\
\text { lecturers }\end{array}$ \\
\hline $\begin{array}{l}\text { Numerical Methods } \\
3^{\text {rd }} \text { Year Degree }\end{array}$ & 20 & 2 & 2.5 & 3 \\
\hline $\begin{array}{l}\text { Technology of Machines for Leveling } \\
1^{\text {st }} \text { Year Master's Degree }\end{array}$ & 14 & 2 & 2.5 & 2 \\
\hline $\begin{array}{l}\text { Materials Behaviour in Service } \\
1^{\text {st }} \text { Year Master's Degree }\end{array}$ & 9 & 2 & 2.5 & 1 \\
\hline
\end{tabular}

Depending on the difficulty of the problem, different submission deadlines and methods were proposed. For example, for Numerical Methods, the deadline proposed was approximately 10 days after the practical session, and the task had to be submitted through the Tasks Platform belonging to the UPV student on-line platform.

\section{RESULTS}

In this Section, the results obtained after the evaluation of the Instrumental Specific competence by means of activities incorporated to the different practical sessions are shown. First, an interesting result obtained from the subjects under study is depicted in Figure 1, where is observed the know-how of the students. It has been measured as success or failure, considering "success" the original results individually presented by each student (accepting small mistakes), while "failure" has been defined as the inability of autonomously solving the problem.
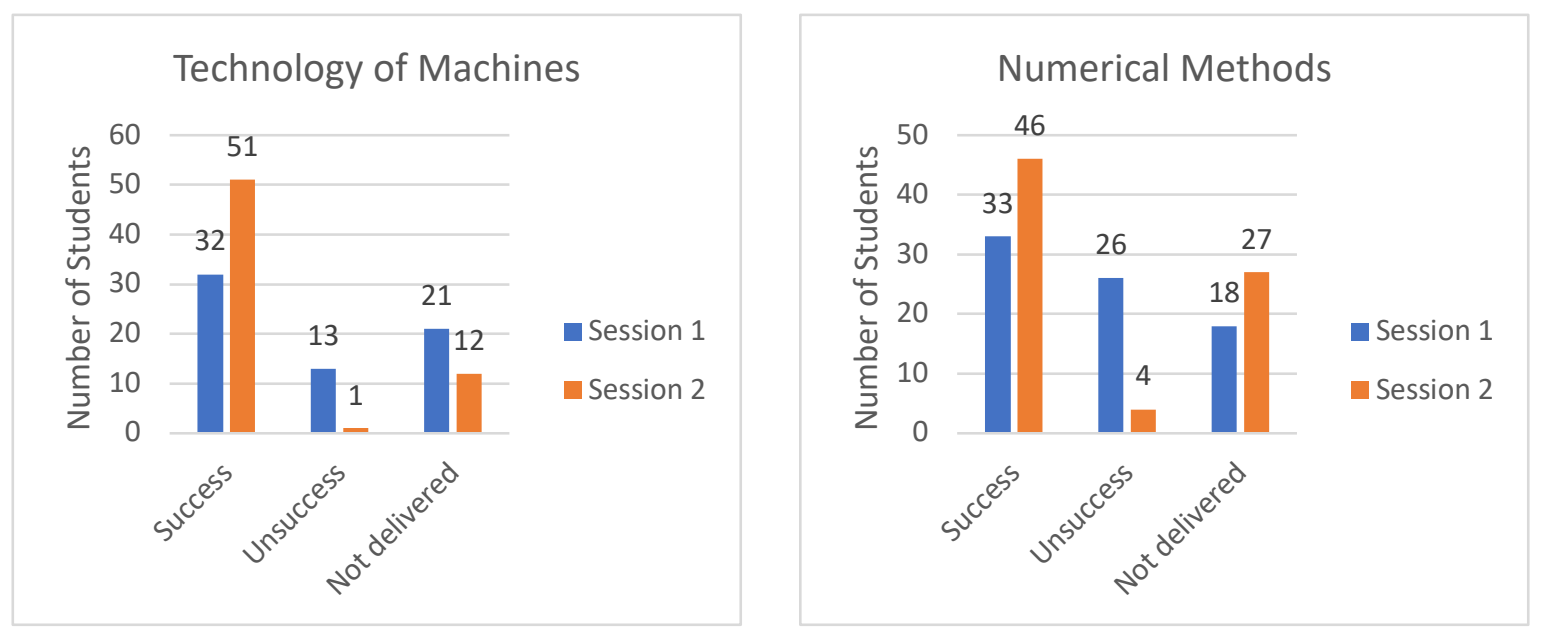

Figure 1. Students' know-how by subject.

Therefore, it can be observed that if we do not take into account the number of students that did not deliver the task, the amount of students that successfully did the work considerably increases in the second practical session. This is due to the fact that the student faces the FE computation with ANSYS $®$ for the very first time in the first session. For this reason, from the results delivered by the students, it can be inferred that in the first session it is too early to suggest this kind of exercise. Thus, 
as an improvement for the Innovation and Educational Improvement Projects (PIME in Spanish) in which is framed the current work, it is proposed to remove the activity related to the first session while retaining the one belonging to the second practical session, including the contents of the former session. At the same time, this decision contributes to offloading students from work outside of practical sessions, since the guided problem proposed in the last session was short enough to allow students to do the activity during the class hour.

Figure 2 shows the comprehension of the work that the Technology of Machines students are carrying out. This has been measured considering (among those that delivered the task) the results and the procedure followed to obtain them. In order to do this rating, the files obtained for the task and the justification of the results provided by the students in the answers form have been assessed. It can be observed that both, the participation and the learning results are considerably higher in the second session, the number of students providing a correct explanation are more than twice than in the first (20 versus 55$)$ and make less mistakes.

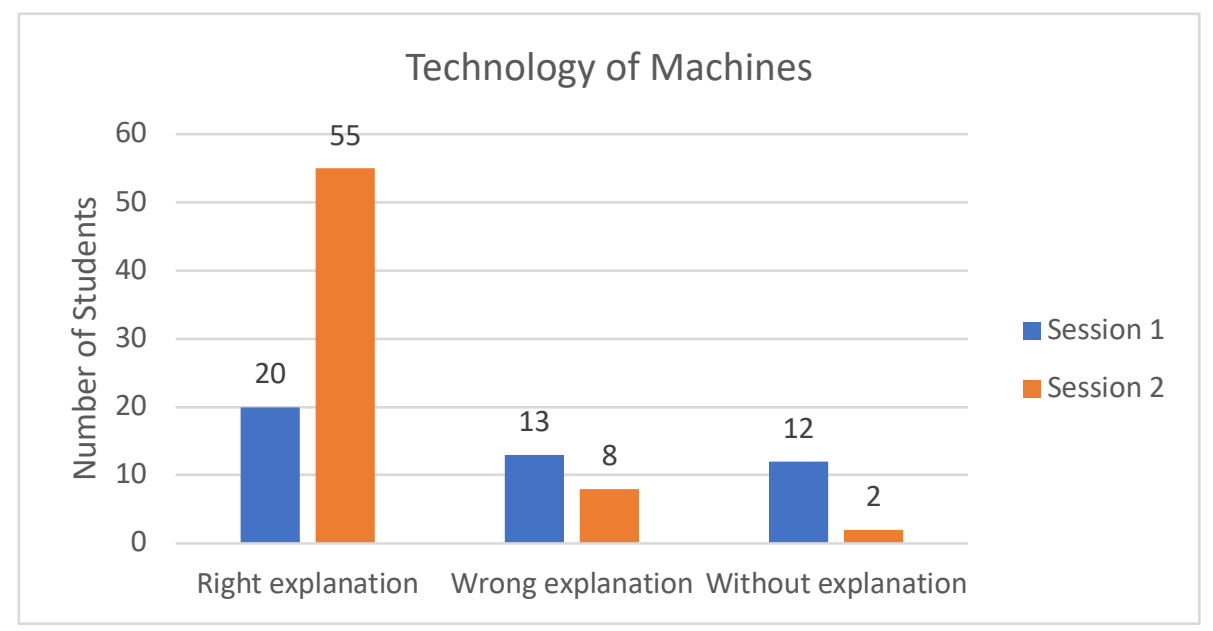

Figure 2. Comprehension of Technology of Machines' students.

The same trend can be observed in the Numerical Methods subject along the practical sessions, the difference being even higher. For this reason, it has been decided to dismiss the results obtained in the first session and only the assessment of Session 2 will be shown for this subject. Despite observing a positive evolution in the students' involvement, the learning results were not satisfactorily reached, as it is shown in Figure 3. Only about half of the students really understood what they were doing, while the other half were able to solve the problem although their comprehension of the problem was not deep enough.

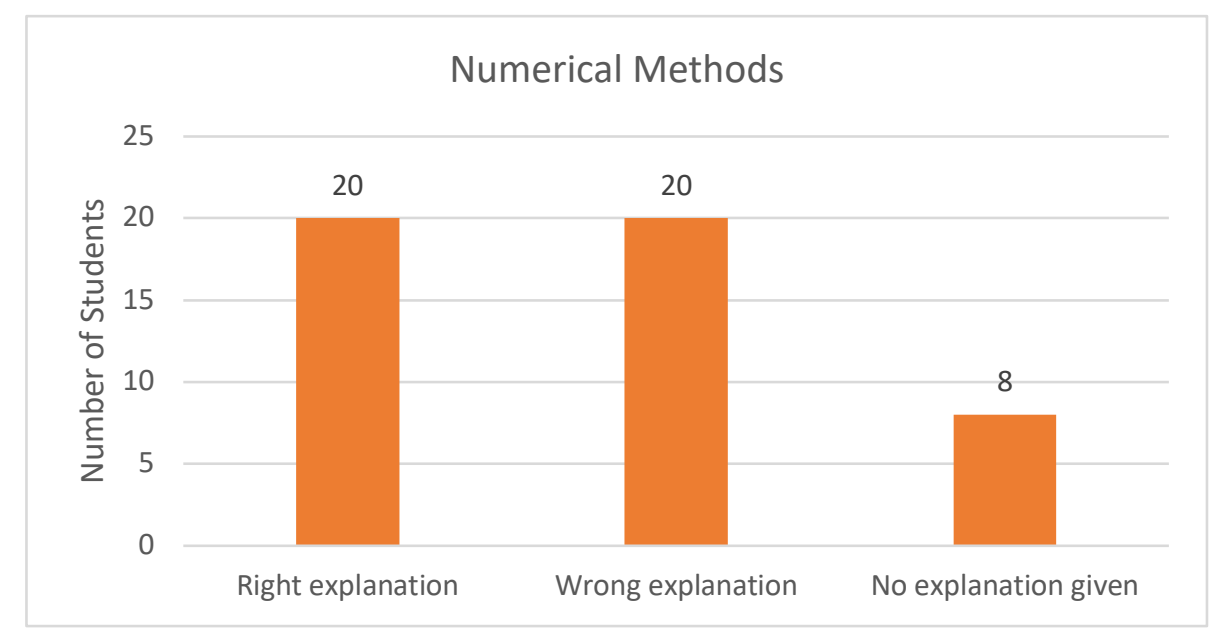

Figure 3. Comprehension of the Numerical Methods' students in Practical Session. 
Now, the mark obtained in the practical sessions was compared to the one reached in the task for the "Specific Instrumental" transversal competence assessment. The mark for the Technology of Machines subject is provided for the mean value of both sessions, while for the Numerical Methods subject, only the Session 2 marks are considered, for the reasons above-mentioned. Aiming to assess the "Specific Instrumental" transversal competence, the ability of the students to synthesize the problem, the mesh, the boundary conditions application and the results explanation, as well as the procedure followed to obtain them have been taken into account. The students that did not delivered the task, were marked with a zero in the corresponding task. The comparison is shown in Figure 4 and a similar trend can be found in both subjects, regardless of whether the average mark is compared or if there is only the mark of the second session. In general, those students obtaining good marks in the practical sessions, achieved good results also in the activities, with some exceptions that can be due to fact that the practical session was carried out in pairs, but the "Specific Instrumental" transversal competence activity is individually evaluated. These exceptions show that it is not possible to measure the acquired competence simply by evaluating the practical session as it has been done so far.
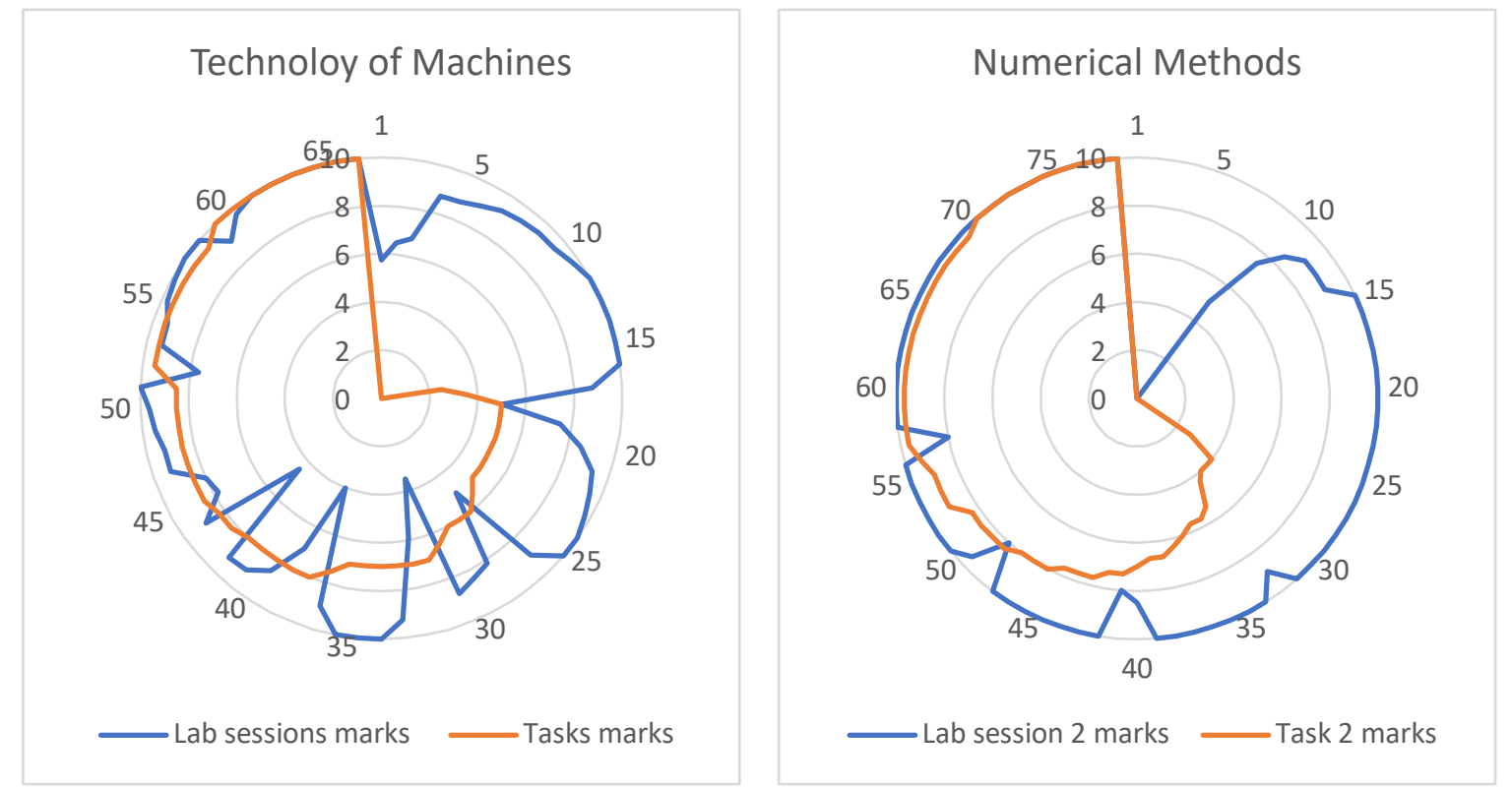

Figure 4. Relationship between the Practical Sessions marks and those corresponding to the evaluation of the Task belonging to "Specific Instrumental" transversal competence.

\section{CONCLUSIONS}

In the current work, the results achieved in different subjects in the Mechanical Engineering field are shown. In these subjects, similar activities have been implemented in the practical sessions with a view to assessing the transversal competence specific instrumental, which measures the degree of acquisition of the skills by the students in working tools used in their professional development. The tool chosen in all the subjects is the commercial program ANSYS $\otimes$, which allows the users to do calculations based in finite elements problems with a known behaviour equation, as in mechanical problems. The strategy used has been the incorporation of a non-guided exercise to the practical sessions that in previous years exclusively followed a reproductive model. The above-mentioned has been adapted to the level and kind of problem solved in each subject and practical session. The initial idea was that students, individually, were able to do the work during each practical session. Nevertheless, experience has shown that maybe it is too early to ask the student about an autonomous management in the first session, taking into account that, for the majority of the students, it is the very first time that they work with a FE program. For this reason, in the Technology of Machines subject, contrary to the initial schedule, the deadline for the task was extended about a week. With this measure, the guarantee of the authenticity of the works is no longer valid, but also the responsibility about the learning is transferred to the students, since they are allowed to spend the amount of time they need to reach the learning results in depth. They can work without the pressure of having to finish the task in the practical session itself. In spite of the fact that the results show a high percentage of incomplete exercises or ones that are badly solved in the first session, they considerably improve in the second, manifesting the expected evolution in the student's learning, 
among other reasons, for the higher level of ability acquired possibly thanks to having to solve a problem without a detailed guide as in the practical session guide.

Regarding the comparative between the results of the activity proposes and those corresponding to the practical session, regardless of the expected correlation for students who are at both sides of the evaluation, it can be observed that the mark of the practical session, in some cases, is not a good indicator of the acquisition degree of the competence. Therefore, it would be an error using it only for the evaluation. The factors that can present some influence in these discrepancies can be, on the one hand, by the collaborative environment among the students and also student-lecturer during the practical sessions and mainly in the development of the practical sessions in pairs, while the tasks are individually carried out.

Furthermore, the experience of this year can serve to redefine some aspects of the activities, such as proposing strategies to define only a task in the second practical session that every student can solve with a guarantee of originality.

\section{ACKNOWLEDGEMENTS}

Authors gratefully acknowledge the financial support of the Vicerrectorado de Estudios, Calidad y Acreditación and the Vicerrectorado de Recursos Digitales y Documentación of the Universitat Politècnica de València (project PIME B/19-20/165) and the Instituto de Ciencias de la Educación of the Universitat Politècnica de València (EICE INTEGRAL).

\section{REFERENCES}

[1] A. Sursock and H. Smidt. Trends 2010: A decade of change in European higher education. Brussels: European University Association, 2010

[2] P. Murias, J.C. De Miguel and D. Rodriguez, "A composite indicator for university quality assesment: The case of Spanish higher education system", Social Indicators research, vol. 89, 129-146, 2007.

[3] J. Young and E. Chapman, "Generic competency frameworks: A brief historical overview", Education Research and Perspectives, vol. 37, no. 1, 1-24, 2010.

[4] P. Beneitone et al, "Tuning brochure, Tuning Project: Reflexiones y perspectivas de la Educación Superior en América Latina. Informe Final-Proyecto Tuning-América Latina". Bilbao: Universidad de Deusto, 2007. Retrieved from http://tuning.unideusto.org/tuningal, 2007

[5] Tuning project. "Tunning General Brochure", Accessed 14 August, 2020. Retrieved form http://www.unideusto.org/tuningeu/documents.html.

[6] UNIVERSITAT POLITĖCNICA DE VALĖNCIA. "Competencias transversales", Accessed 14 August, 2020. Retrieved from http://www.upv.es/contenidos/COMPTRAN/.

[7] ANECA. "Programas de evaluación ACREDITA", Accessed 14 August, 2020. Retrieved from http://www.aneca.es/Programas-de-evaluacion/Evaluacion-de-titulos/ACREDITA.

[8] ABET, "Accreditation Criteria \& Supporting Documents", Accessed 14 August, 2020. Retrieved from https://www.abet.org/accreditation/accreditation-criteria/.

[9] O.C. Zienkiewicz and R.L. Taylor, The Finite Element Method for Solid and Structural Mechanics. $6^{\text {th }}$ ed. Oxford: Elsevier/Butterworth-Heinemann, 2006.

[10] ANSYS, Accessed 14 August, 2020. Retrieved from https://www.ansys.com/ 